\section{Response to 'Correspondence to viewpoint 'Defining refractory rheumatoid arthritis' by Buch' by Roodenrijs et al}

I would like to thank Roodenrijs et al ${ }^{1}$ for their thoughtful comments on my viewpoint 'Defining refractory rheumatoid arthritis ${ }^{2}$ and appreciate their acknowledgement of this important subgroup of patients with unmet clinical needs.

The authors highlight their description and recent review of 'difficult to treat $\mathrm{RA}^{3}$ that in contrast to my viewpoint includes refractory rheumatoid arthritis (RA) in the presence of persistent inflammation and in its absence. I acknowledge this approach is more inclusive in encompassing the breadth of reasons that contribute to challenging RA treatment decision making in realworld practice and as such would consider 'difficult to treat RA' more of an umbrella term.

In my viewpoint, I a priori focused on the concept and subgroup of intrinsic refractory RA disease that (as with other diseases such as refractory cancer) tacitly implies persistent (RA) pathology (be it local \pm systemic) in the face of available therapeutic interventions. Such a subgroup is likely to be rare; the majority of biological refractory individuals demonstrate both inefficacy and intolerance to successive therapeutic interventions (as illustrated in a first report from the British Society of Rheumatology Biologic Register ${ }^{4}$ ). The viewpoint was thus necessarily more directed and discussed how best to identify the rare refractory disease group to deliver on the overarching objective of its biological characterisation and mitigate against inclusion of solely non-inflammatory drivers. Precision medicine principally relies on a pathogenesis-driven approach to treatment selection. Ultimately, final treatment decisions in clinical practice would be an integration of such a pathologically driven rationale, with consideration of the wider patient profile (lifestyle and comorbidity) and indeed contextual factors that may also coexist and contribute to 'difficult to treat RA'.

I would acknowledge that distinguishing such refractory disease through presence or absence of antidrug antibody (ADA) is clinically problematic. There remains a continued knowledge gap in how best to translate the profusion of ADA data into clinical practice, with issues in assay robustness and standardisation, the definition of cut-off values to define ADA and therapeutic drug levels as well as its interpretation. ${ }^{5}$ Nevertheless, as part of this ongoing research agenda, it remains important to evaluate for ADA when otherwise refractory RA disease may be erroneously ascribed to incorrect drug targeting.

In summary, I would consider my viewpoint as complementary to Roodenrijs et al's comments and prior review. I welcome the
European League Against Rheumatism initiative as a pragmatic and important first step towards improving the understanding and management of the wider concept of 'difficult to treat' RA. It is likely that further iterations will be needed as more of an evidence base emerges, with refined evaluation of specific areas such as refractory RA disease.

Maya H Buch ${ }^{1,2}$

${ }^{1}$ Leeds Institute of Rheumatic and Musculoskeletal Medicine, University of Leeds, Leeds, UK

${ }^{2}$ NIHR Leeds Biomedical Research Centre, Leeds Teaching Hospitals NHS Trust, Leeds, UK

Correspondence to Professor Maya H Buch, Leeds Institute of Rheumatic and Musculoskeletal Medicine, University of Leeds, Leeds LS7 4SA, UK; m.buch@leeds.ac.uk

Handling editor Josef S Smolen

Contributors MHB was the sole author of the submitted electronic letter.

Competing interests None declared.

Patient consent Not required.

Provenance and peer review Commissioned; internally peer reviewed.

(C) Author(s) (or their employer(s)) 2019. No commercial re-use. See rights and permissions. Published by BMJ.

\section{Check for updates}

To cite Buch MH. Ann Rheum Dis 2019;78:e106.

Received 28 July 2018

Revised 31 July 2018

Accepted 2 August 2018

Published Online First 17 August 2018

\section{G Linked}

- http://dx.doi.org/10.1136/annrheumdis-2018-214147

Ann Rheum Dis 2019;78:e106. doi:10.1136/annrheumdis-2018-214153

\section{REFERENCES}

1 Roodenrijs NMT, de Hair MJH, van der Goes MC, et al. Response to viewpoint 'Defining refractory rheumatoid arthritis' by Buch. Ann Rheum Dis 2019;78:e105.

2 Buch MH. Defining refractory rheumatoid arthritis. Ann Rheum Dis 2018;77:966-9.

3 de Hair MJH, Jacobs JWG, Schoneveld JLM, et al. Difficult-to-treat rheumatoid arthritis: an area of unmet clinical need. Rheumatology 2017. doi: 10.1093/rheumatology/ kex349. [Epub ahead of print 4 Oct 2017].

4 Kearsley-Fleet L, Davies R, De Cock D, et al. BSRBR-RA Contributors Group. Biologic refractory disease in rheumatoid arthritis: results from the British Society for Rheumatology Biologics Register for Rheumatoid Arthritis. Ann Rheum Dis 2018:77:1405-12.

5 Vincent FB, Morand EF, Murphy K, et al. Antidrug antibodies (ADAb) to tumour necrosis factor (TNF)-specific neutralising agents in chronic inflammatory diseases: a real issue, a clinical perspective. Ann Rheum Dis 2013;72:165-78. 